See discussions, stats, and author profiles for this publication at: https://www.researchgate.net/publication/23169367

\title{
Topology of Schwann cells and sympathetic innervation along preglomerular vessels: A confocal microscopic study in protein S100B/EGFP transgenic mice
}

Article in American journal of physiology. Renal physiology · September 2008

DOI: 10.1152/ajprenal.00599.2007 · Source: PubMed

6

4 authors, including:

(2.) Fannie Darlot

French Institute of Health and Medical Research

19 PUBLICATIONS 177 CITATIONS

SEE PROFILE

Some of the authors of this publication are also working on these related projects:

Project Near infrared for Parkinsons NIR View project 


\title{
Topology of Schwann cells and sympathetic innervation along preglomerular vessels: a confocal microscopic study in protein S100B/EGFP transgenic mice
}

\author{
Fannie Darlot, ${ }^{1}$ Annie Artuso, ${ }^{1}$ Nicole Lautredou-Audouy, ${ }^{2}$ and Daniel Casellas ${ }^{1}$ \\ ${ }^{1}$ Groupe Rein et Hypertension (EA3127), Institut Universitaire de Recherche Clinique (IURC), and ${ }^{2}$ Centre Régional \\ d'Imagerie Cellulaire, IURC, Montpellier, France
}

Submitted 18 December 2007; accepted in final form 11 August 2008

\begin{abstract}
Darlot F, Artuso A, Lautredou-Audouy N, Casellas D. Topology of Schwann cells and sympathetic innervation along preglomerular vessels: a confocal microscopic study in protein S100B/EGFP transgenic mice. Am J Physiol Renal Physiol 295: F1142-F1148, 2008. First published August 20, 2008; doi:10.1152/ajprenal.00599.2007.— Schwann cells ( $\mathrm{Sc}$ ), associated axons, and nearby vascular endothelium constitute a functional trilogy of major importance during the development and regrowth of peripheral vascular nerves. The goal of the present study is to provide a technique of triple fluorescence confocal imaging of these cell types along renal preglomerular vessels. We took advantage of a protein S100B/EGFP transgenic mouse to visualize Sc. The endothelium was labeled with an intravenous injection of fluorescently tagged lectin, and after tissue processing, adrenergic nerves were revealed with an antibody against the marker protein synaptophysin. As a validation step, we found that EGFPpositive perivascular cells with prominent cell bodies and extensive, multidirectional cell processes were protein S100B positive. They were identified as Sc and indirectly assumed to be unmyelinated Sc. By contrast, we found strong EGFP expression in proximal epithelial cells and in the epithelium lining thin limbs of Henle. This epithelial fluorescence was not associated with immunoreactive protein S100B and thus corresponded to ectopic EGFP expressions in this mouse strain. Sc were organized in bundles or as a meshwork surrounding the preglomerular vasculature from arcuate arteries to afferent arterioles. No Sc were detected in the medulla. Although most Sc were closely apposed to adrenergic varicosities, many varicosities were not associated with detectable Sc processes. The present technique, and the capacity of confocal microscopy to yield three-dimensional imaging, allow the study of the microtopology of Sc and related sympathetic axons in the renal perivascular interstitium.
\end{abstract}

immunohistochemistry; triple fluorescence labeling; synaptophysin; Griffonia simplicifolia; isolectin; myelinated and unmyelinated nerves

RECENT STUDIES UNDERLINE THE crucial role played by Schwann cells (Sc) in the development and maturation of peripheral sympathetic nerves $(5,21)$. Functional interactions between Sc and axons are also present during posttraumatic axonal regrowth $(5,7)$. In this respect, the addition and/or migration of Sc within artificial nerve guides appears as an essential determinant of axonal regrowth $(13,26,43)$. In addition, recent studies establish the existence of common molecular mechanisms that link axonal and vascular guidance during early development $(1,31,33,34,38)$, during posttraumatic axonal regrowth (20), and during tumoral angiogenesis $(4,34)$. The existence of such a "functional trilogy" among Sc, axons, and vascular endothelial cells gives relevance and importance to

Address for reprint requests and other correspondence: D. Casellas, Groupe Rein et Hypertension, IURC, 641 Ave. Doyen Giraud, 34093 Montpellier Cédex 5, France (e-mail: casellas@iurc.montp.inserm.fr). the possibility of specifically, and simultaneously, imaging these three cell types in normal and pathological animal models.

Transmission electron microscopy (TEM) and immunohistochemistry have provided precise characterizations of renal nerves regarding topology, nature of nerve transmitters, and ultrastructure $(3,29)$. The relationships between axons and myelinated or unmyelinated Sc have been recently documented with TEM on sections of the extrinsic renal nerves of mice and rats $(36,37)$. Furthermore, images of TEM sections showing unmyelinated Sc and the associated axons in the vicinity of intrarenal arteries and afferent arterioles have been published (e.g., Refs. 3 and 42 Fig. 3.15, p. 63). However, a method allowing a direct three-dimensional observation of Sc/axons/ vessels in large portions of the kidney is yet to be proposed.

Recent techniques permit targeted manipulations of the mouse genome (45). They allow the insertion of sequences coding for the enhanced green fluorescent protein (EGFP) under the control of a gene promoter whose activity can thus be assessed in its in vivo, complex physiological environment. Such EGFP-tagged mice have recently been created under the control of a promoter sequence of the mouse gene coding protein S100B (S100B/EGFP transgenic mice) (46). This mouse strain has thus far exclusively been used in studies of the central nervous system $(17,46)$. Many in vivo or in vitro studies on Sc associated with peripheral nerves have relied on protein $\mathrm{S} 100$ as a cell marker $(13,25,27,32,39,43)$. In fact, protein S100 is recognized as a recurrently expressed cell factor along the Sc lineage from precursor/immature to both myelinated or unmyelinated $\operatorname{Sc}(5,11,22,25,35)$. In addition, transgenic mice in which the cyan fluorescent protein is expressed under the control of transcriptional regulatory sequences of the human S100B gene (i.e., "Kosmos" mice, Jackson, ME) have successfully been used to monitor Sc migration within peripheral nerve grafts (19). With this background in mind, we hypothesized that S100B/EGFP transgenic mice could provide a way of direct light microscopic imaging of Sc associated with intrinsic renal vascular nerves.

The present studies were undertaken using the renal vasculature of S100B/EGFP transgenic mice with the aims to validate and to illustrate a technique of triple fluorescent labeling of Sc/sympathetic innervation/endothelium, using confocal microscopy.

\section{MATERIALS AND METHODS}

Animals. Ten male transgenic mice whose EGFP reporter gene is controlled by the sequence $-1669 /+3106$ of the murine gene se-

\footnotetext{
The costs of publication of this article were defrayed in part by the payment of page charges. The article must therefore be hereby marked "advertisement" in accordance with 18 U.S.C. Section 1734 solely to indicate this fact.
} 
quence of protein S100B (46), with body weights of 25-30 g (7-13 wk), were used. Creation of this transgenic strain was previously described and validated $(17,46)$. Mice were screened for proper EGFP expression using an UV lamp (Tansilluminator UVP model 20, at $312 \mathrm{~nm}$ ) since ear and finger cartilages of S100B/EGFP-positive mice emit green light.

All studies complied with all relevant European and French laws and with the guiding principles for experimental procedures as set forth in the Declaration of Helsinki.

Protocol. Mice were anesthetized with pentobarbital sodium (50 $\mathrm{mg} / 100 \mathrm{~g}$ body wt ip). The right jugular vein was catheterized (PE-10, Clay Adams), and whole-body vascular endothelium was labeled with an intravenous injection of the isolectin IB4 Griffonia simplicifolia coupled to Alexa Fluor $568(100 \mu \mathrm{g} / 100 \mu \mathrm{l}$ saline, ref. I-21412, Molecular Probes). After 10-15 min of recirculation, the animals were killed, and the kidneys were removed and fixed by immersion in buffered formalin (Accustain, Sigma-Aldrich). In pilot studies, we found that paraffin processing compromised EGFP fluorescence. Kidney sections $(10-50 \mu \mathrm{m}$ thick) were thus cut with a vibratome (Leica VT 1000E)

Immunofluorescence. All dilutions were made in PBS containing $2 \%$ bovine serum albumin. Vibratome sections were first incubated for $20 \mathrm{~min}$ at room temperature with 5\% normal goat serum and then overnight at $4^{\circ} \mathrm{C}$ with one of the two primary antibodies used (i.e., anti-protein S-100B or anti-synaptophysin). Of note, these polyclonal antibodies, both having been generated in rabbits, could not be used concurrently in the same section.

To validate the present study, we assessed whether the reporter gene (i.e., EGFP) and protein S100B were coexpressed in the same cell type. For this purpose, sections were labeled with a rabbit polyclonal antibody directed against protein S100 isolated from cow brain (dilution 1:1,000, ref. Z0311, DakoCytomation). This antibody has been repeatedly used to label Sc $(11,13,20,25,39,43)$ and essentially recognizes protein S100B isoform $(25,46)$. Thereafter, sections were incubated for $2 \mathrm{~h}$ at room temperature with an antirabbit antibody from a donkey and coupled to Alexa Fluor 647 (dilution 1:500, ref. A31573, Molecular Probes). Sections were mounted in a drop of Dako Fluorescent Mounting Medium, and coverslips were fixed to the glass slide with nail polish.

In a series of studies, sympathetic nervous varicosities were identified as previously described (6) using a polyclonal rabbit antibody to human synaptophysin $\left(24 \mathrm{~h}\right.$ incubation at $4{ }^{\circ} \mathrm{C}$, dilution $1: 100$, ref. A0010, Dako). Thereafter, this primary antibody was revealed with the same secondary antibody used to label protein S100B.

Negative controls for immunostaining were obtained by omitting primary antibodies.

In some mice, early branches of the renal artery were microdissected, flattened, and fixed with formalin between a coverslip and a glass slide. Once fixed, flat vascular samples were mounted as previously detailed, and the EGFP-positive cells located at the surface of the adventitia were viewed en face with a confocal microscope.

Confocal laser-scanning microscopy. Preparations were observed through an Optiphot-2 upright microscope (Nikon) equipped with high numerical aperture (NA) Nikon objectives (Plan Apo $\times 10,0.45$ NA; Plan Apo $\times 20,0.75$ NA; Fluor $\times 40,1.30$ NA, oil; Plan Apo $\times 60,1.40 \mathrm{NA}$, oil), connected to the confocal Bio-Rad MRC 1024 system (Bio-Rad Life Science Research). A 15-mW argon-krypton laser provided three excitation lines at 488 (EGFP green), 568 (lectin, red), and $647 \mathrm{~nm}$ (synaptophysin or protein S100B, blue).

Images were produced sequentially and collected by two separate photomultipliers to avoid cross-contamination of fluorochromes. Images were scanned at $1,024 \times 1,024$ pixels along an 8 -bit gray scale

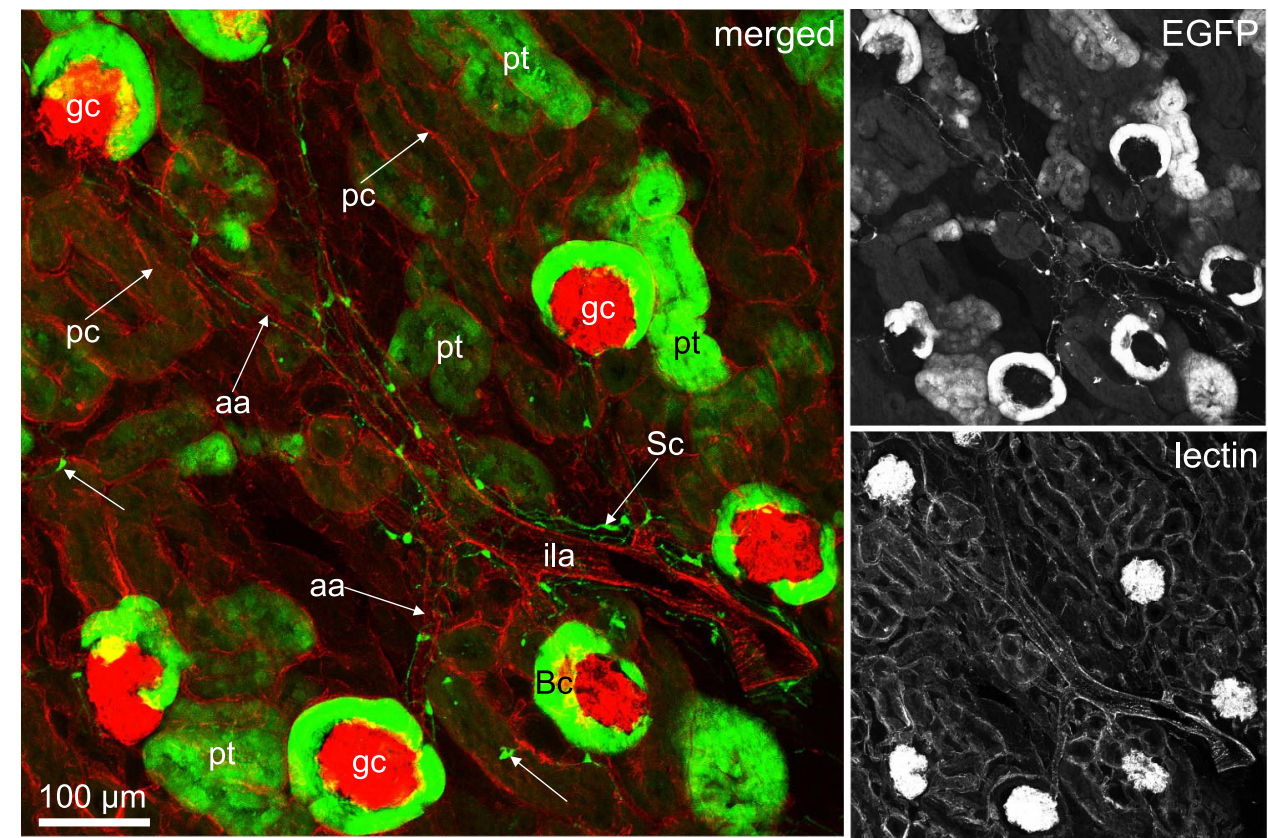

Fig. 1. Low-power confocal images of a midcortical area of an S100B/enhanced green fluorescent protein (EGFP) transgenic mouse $(\times 10$ objective, 73 optical sections, $0.5-\mu \mathrm{m}$ thickness). This figure provides a representative example of the anatomy and cortical distribution of EGFP-positive cells (EGFP panel) and that of lectin-labeled vascular endothelial cells (lectin panel). The merged panel combines the color-coded EGFP (green) and lectin (red) panels. Lectin injection unveils the vascular anatomy (lectin and merged panels). In these low-power views (lectin and merged panels), an interlobular artery (ila; merged panel) gives rise to a series of afferent arterioles (aa), some being connected to glomerular capillaries (gc). Note the prominent lectin labeling of the glomerular capillaries and the dense network of peritubular capillaries (pc) in the rest of the field (merged and lectin panels). Examination of EGFP expression (EGFP and merged panels) reveals 3 distinct cell types: 1) a strong expression is present in cuboidal epithelial cells dwelling in the parietal layer of Bowman's capsules (Bc); 2) in proximal epithelial cells (pt); and 3) in cells located around the preglomerular vessels (Schwann cells; Sc), organized as a network, and characterized by prominent cell bodies, and connected, multiple, elongated cell processes (i.e., identified as Sc). Some of these cells were occasionally found in tubular locations (merged panel, unlabeled arrows). 


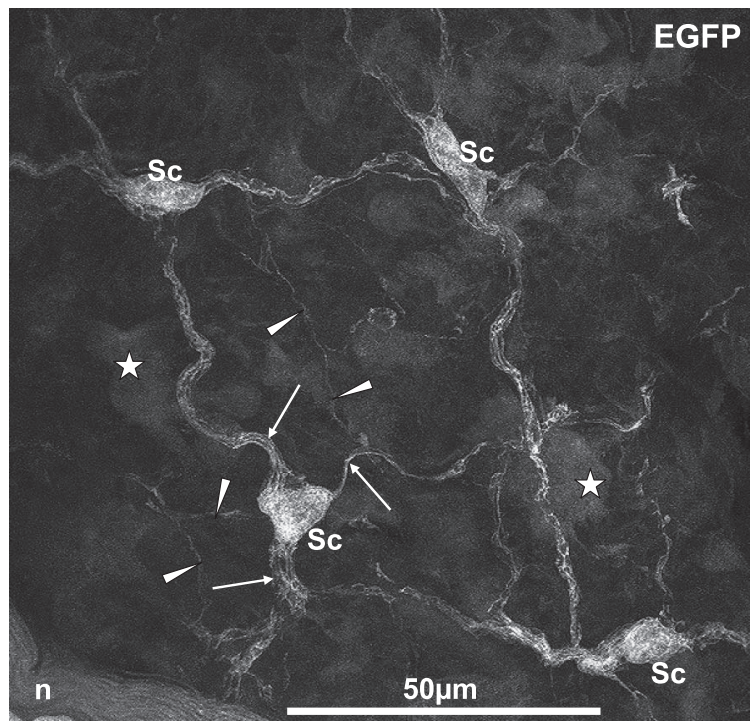

Fig. 2. High-power $(\times 60)$ image of the EGFP fluorescence of a portion of an early branch of the renal artery of a S100B/EGFP transgenic mouse. The artery was fixed flat, confocal settings were adjusted for maximal resolution and signal-to-noise ratio, and an en face observation was performed from the adventitia as described in MATERIALS AND METHODS. This figure details the phenotypic traits of the cells identified as Sc in Fig. 1. In this field, $4 \mathrm{Sc}$ are arranged as a meshwork at the surface of the adventitia. They have prominent cell bodies $(\mathrm{Sc})$ and multiple cell processes of variable thicknesses. Three large cell processes of Sc in the bottom left are indicated by white arrows, whereas tiny ones are indicated by arrowheads. Note the presence within the adventitia of other cells with a weaker EGFP signal; 2 are indicated by white stars. Note the presence of an EGFP-positive nerve (n) running alongside the vessel in the bottom left corner.

in the $X-Y$ plan. Optical sections were made along the $Z$-axis with a resolution of $0.3-1.0 \mu \mathrm{m}$. Images were acquired with Bio-Rad station software, and stacks of digitized optical sections were stored on CDs. Numerical image processing was carried out with Confocal Assistant software (freely available at www.cs.ubc.ca/spider/ladic/confocal. html). Of note, and to achieve maximal sharpness and signal-to-noise ratio as displayed in Fig. 2, 29 successive optical sections of $0.3-\mu \mathrm{m}$ thickness were merged. Each optical section was obtained by averaging 16 successive laser scans to reduce optical noise in the photomultiplier.

\section{RESULTS}

Renal distribution of EGFP-expressing cells and anatomic identification of $S c$. Figure 1 illustrates the cortical distribution of EGFP-expressing cells and the corresponding lectin-tagged vasculature within the renal cortex (merged panel). Lectin injection (lectin panel) sharply delineates endothelial cell margins within an interlobular artery, afferent arterioles, and peritubular capillaries and strongly stains glomerular capillary tufts. In the corresponding EGFP panel, a strong EGFP fluorescence appears within the cuboidal epithelial cells that are known to populate an appreciable fraction of the parietal side of Bowman's capsules in mice (48) and extends with lesser intensity along proximal tubular loops. Other EGFP-positive cell types are observed aside from epithelial cells (Fig. 1). They are characterized by prominent ellipsoidal cell bodies (i.e., corresponding to nuclear bulging; data for nuclear staining not shown) and exhibit interconnected, extensive cell processes (EGFP panel). These cells are located within the perivascular interstitium where they form a loose meshwork around arteries and arterioles (Fig. 1, merged panel). On pure anatomic grounds $(15,25,27,28,39)$, these cells likely represent the Sc population located within the renal cortex. Figure 2 illustrates at a higher power and spatial definition the phenotypic traits of these Sc.

Medullary structures were also examined (Fig. 3, left). Strong EGFP fluorescence was found in tubular epithelial cells starting at the limit between the outer and inner stripes of the outer medulla. Based on their localization and morphology, these cells (Fig. 4, right) represent the thin limbs of Henle (24, 41). No EGFP-positive cells with prominent ellipsoidal cell bodies and interconnected, extensive cell processes were detected in medullary structures (Fig. 3, left and right).

Validation studies. To validate EGFP as a reporter gene, we assessed which of these EGFP-positive cell types simultaneously expressed immunoreactive protein S100B, a "classic" marker protein of Sc $(13,25,27,32,39,43)$. As illustrated in the portion of the renal cortex shown in Fig. 4, EGFP-expressing cells outnumbered the cells revealed by immunoreactive protein S100B (right), thus demonstrating the presence of ectopic EGFP expression in some cell types. The merged panel of Fig. 4 demonstrates that only EGFP-positive cells previ-

Fig. 3. Confocal images of medullary structures of an S100B/EGFP transgenic mouse. In both panels, EGFPpositive cells appear in green, and lectin-labeled peritubular capillaries appear in red. Left: low-power view ( $\times 10$ objective, 39 optical sections, $1-\mu \mathrm{m}$ thickness) showing a portion of the inner cortex (ic), the urinary space (us), the outer medulla (om), and its division into outer and inner stripes (os and is, respectively). The limit between os and is (white dotted line) was drawn on the basis of changes in the pattern of peritubular capillaries $(24,47)$. The strongly EGFPpositive tubules visible beyond that limit correspond to the thin limbs of Henle $(24,41)$. Unlike what was found within the cortex (Fig. 1, left), note the absence of Sc cells in medullary structures. Right: enlarged view of EGFP-positive tubules coursing the inner stripe $(\times 20$ objective, 21 optical sections, $1-\mu \mathrm{m}$ thickness), showing thin-walled epithelial cells with bulging nuclear area.
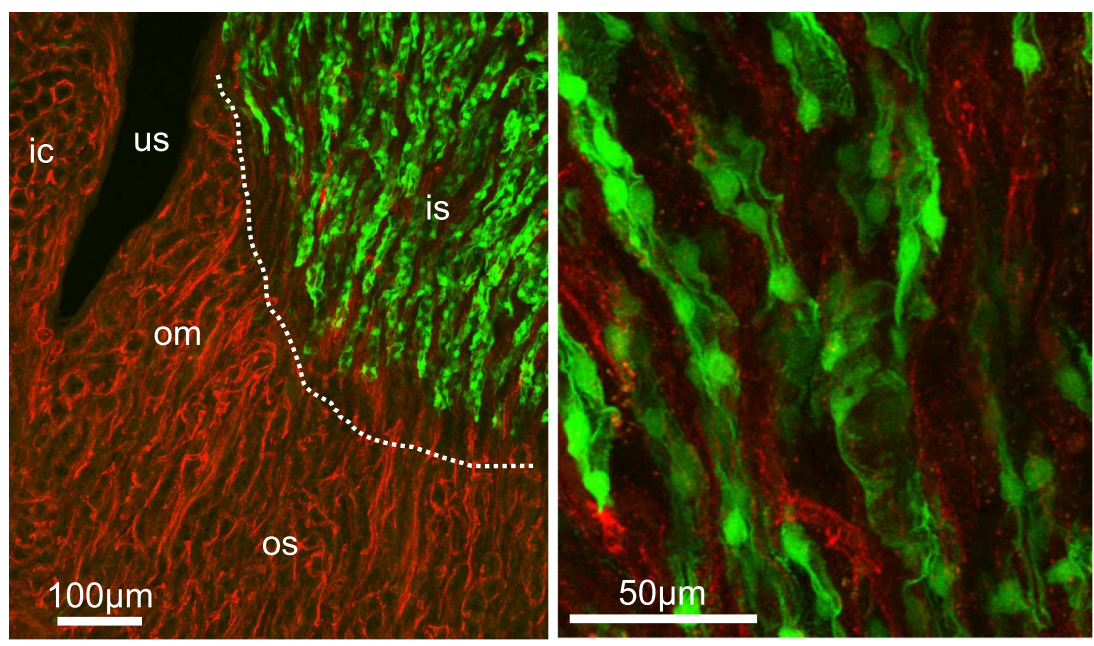

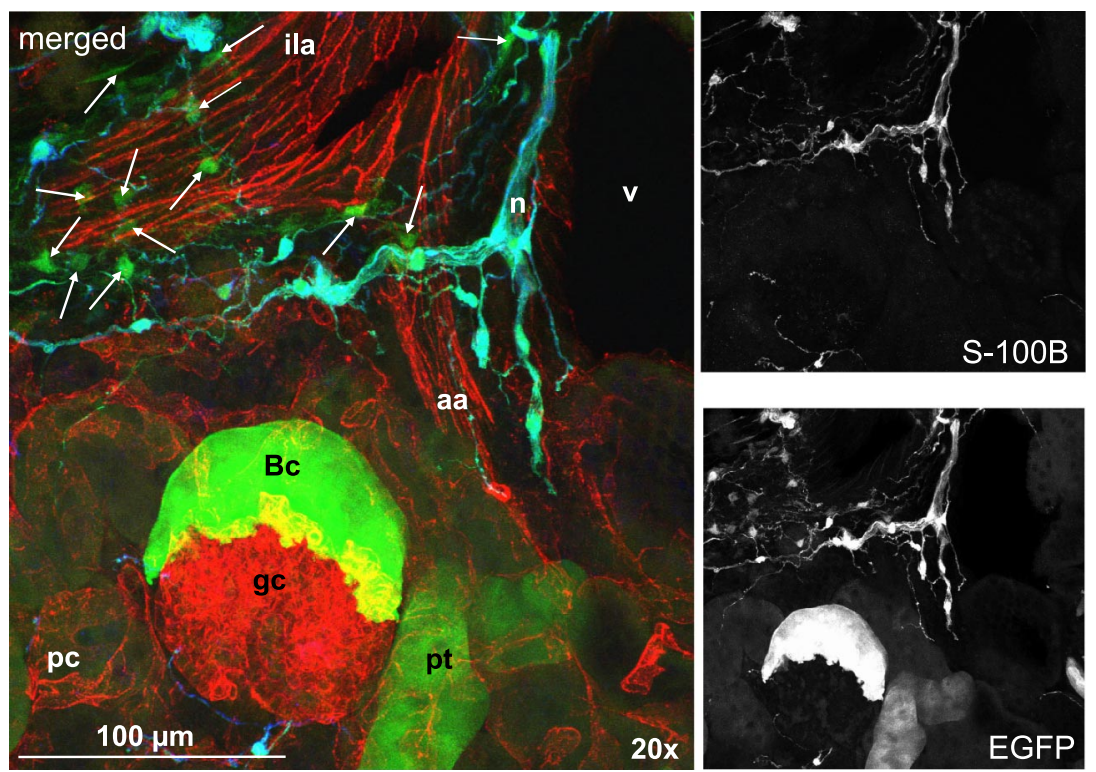

Fig. 4. Confocal images of the juxtamedullary area of a S100B/EGFP transgenic mouse $(\times 20$ objective, 37 optical sections, $1-\mu \mathrm{m}$ thickness). This figure illustrates the distribution of immunoreactive protein S100B (S100B panel) and that of EGFP (EGFP panel). It is noteworthy that EGFP is more abundant than protein S100B due to ectopic expression of the former. The merged, polychromic panel (left) underlines the differences in distributions of protein S100B (blue) and EGFP (green) and adds endothelial labeling (red; ila, interlobular artery; aa, afferent arteriole; gl, glomerular cap-

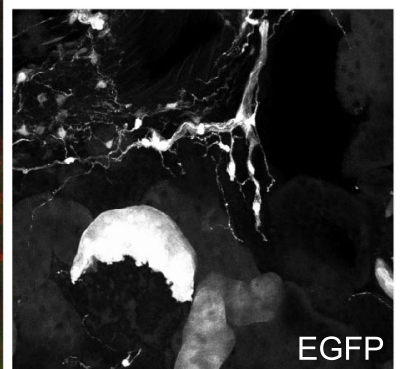
illaries; pc, peritubular capillaries; v, venous profile). Epithelial cells that cover the top of Bowman's capsule $(\mathrm{Bc})$ and proximal tubular cells (pt) only express EGFP. A series of cells designated by white arrows and located at the vascular adventitia only express EGFP. By contrast, cells appearing in light blue express both markers. They exhibit the phenotypic characteristics of Sc cells shown in Fig. 2 and merge into a nerve in the perivascular space (n). Of note, all structures that appear in the S100B panel also expressed EGFP and thus appear in light blue in the merged panel.

ously identified as Sc (see above, Figs. 1 and 2) on the basis of distinct anatomic features concurrently expressed both proteins. By contrast, the epithelial cells populating Bowman's capsules, proximal tubules, and some cells dwelling in the vascular adventitia (Fig. 4, merged panel, white arrows) had an ectopic EGFP expression, not accompanied by the expression of protein S100B.

Figure 5 (merged panel) confirms and extends these results to the dense population of Sc located within the pelvic mucosa. Furthermore, it demonstrates that EGFP-positive thin limbs of Henle do not express protein S100B, as we previously observed with the EGFP-positive epithelial cells of Bowman's capsules and proximal tubules (see above, Fig. 4).

Microtopology of Sc and sympathetic axons along the vasculature and pelvic mucosa. We next examined the topological relationships between EGFP-positive cells identified as Sc and sympathetic axons labeled for synaptophysin. Figure $6 A$ provides a merged image in which endothelial lectin labeling appears in red, axons appear in blue, and EGFP-positive cells appear in green. Note the strong ectopic expression of EGFP in Bowman's capsules and proximal tubules. Lectin labeling sharply outlines endothelial cell margins and reveals an interlobular artery (ila) connected to three afferent arterioles (white stars). Sc, whose bulging nuclear area is indicated by arrows, are loosely arranged around the artery and arterioles. Note that in several areas, many adrenergic varicosities appear as isolated "blue bags" and are not connected to any visible Sc processes. On the other hand, and as shown on a higher-power view of the lower afferent arterioles (Fig. 6B), many varicosities are indeed closely apposed to Sc (arrows and single arrowheads), facing the smooth muscle cell layer. Similar observations were made in larger arcuate arteries (data not shown).

The examination of Sc present within the pelvic mucosa (see above, Fig. 5) and the assessment of their relationships with adrenergic varicosities were also performed as the observation of the mucosa is favored by its flat, twodimensional geometry. An "en face" view of the pelvic mucosa is given in Fig. 7. As was observed in vessels (see above, Fig. 6), many nervous varicosities were lined up along Sc processes but, again, some varicosities remained free of visible Sc processes (Fig. 7). Furthermore, and contrasting with the Sc topology observed within the renal
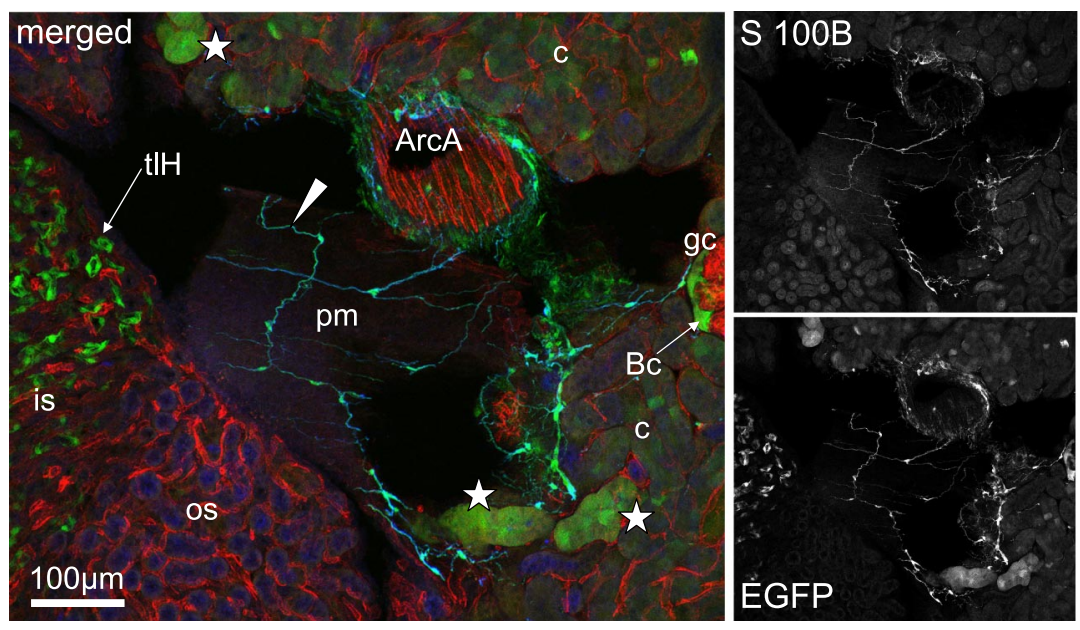

Fig. 5. Confocal images of a thick kidney section of an S100B/EGFP transgenic mouse $(\times 10$ objective, 37 optical sections, $1-\mu \mathrm{m}$ thickness). In the merged panel, this transversal section reveals part of the juxtamedullary cortex (c) with the glomerulus $(\mathrm{gc})$, part of the outer and inner stripes of the outer medulla (os and is, respectively), and a portion of the pelvic mucosa (pm). As was previously observed in the cortex (Fig. 4), EGFP-expressing cells (EGFP panel) outnumber protein S100B-expressing cells (S100B panel), demonstrating ectopic EGFP expression in some cell types that appear in green in the merged panel. In the merged panel, and as was found previously (Fig. 4), parietal epithelial cells of Bowman's capsule $(\mathrm{Bc})$, epithelial cells of proximal tubules (stars), some advential cells of the arcuate artery (ArcA), expressed EGFP only. This is also true for the epithelial cells lining thin limbs of Henle (tlH). Sc which coexpress protein S100B and EGFP appear in light blue. As in Fig. 3, Sc are visible around the arcuate arterial profile (ArcA) and in the cortex, but, in addition, they organize themselves as a network within the pelvic mucosa (white arrowhead). 

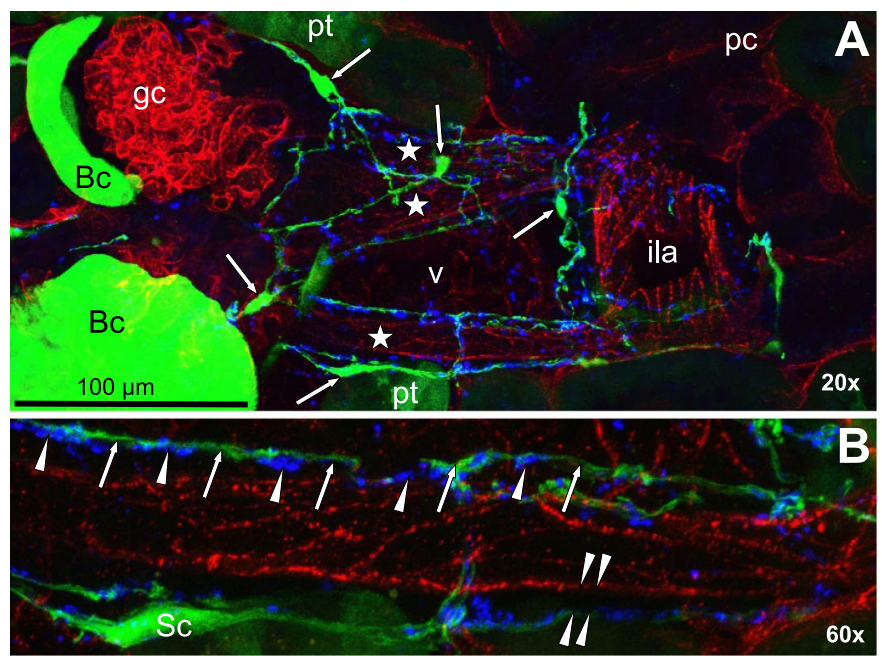

Fig. 6. Perivascular distribution of Sc and immunostained adrenergic axons along preglomerular vessels: $B$ : picture taken at high magnification $(\times 60$ objective, 32 optical sections, $0.5-\mu \mathrm{m}$ thickness) of the bottom portion of $A$ ( $\times 20$ objective, 72 optical sections, $0.5-\mu \mathrm{m}$ thickness). Green was given to cells expressing EGFP. Sc with their long cytoplasmic processes are indicated by white arrows $(A$ and $B)$ and a cell body $(\mathrm{Sc})$ is shown in $B$. Sc are located within the interstitial space around arteries and arterioles. Epithelial cells with ectopic expression of EGFP are visible within 2 Bowman's capsules $(\mathrm{Bc})$ and in proximal tubules (pt). Endothelial cells appear in red (pc, peritubular capillaries; gc, glomerular capillaries; ila, interlobular artery; v, interlobular vein; white stars, afferent arterioles). Blue was given to immunoreactive synaptophysin that labels varicosities of adrenergic axons (6). In $B$, synaptophysin deposits are sometimes not associated with any visible Sc processes. Furthermore, alternate distribution of varicosities and Sc processes (white arrowheads and white arrows, respectively) appear in $B$. Opposed pairs of white arrowheads indicate the space occupied by vascular smooth muscle cells, not labeled in this preparation.

cortex (see above, Figs. 1 and 6), Sc and strings of varicosities were not solely organized around vessels but were distributed throughout the mucosa (Fig. 7).

Three-dimensional observation of Sc and related vessels. One advantage of confocal microscopy is to generate serial optical sections through thick tissue samples. Furthermore, stereo pairs can be computed from the stacks of serial sections, color coded in blue and red, and merged as a single anaglyphic view. A three-dimensional, subjective rendering of such views can be achieved by wearing glasses equipped with red (left eye) and cyan (right eye) filters, which limit each eye's vision to the respective "left" or "right" image contained within the merged pair. Supplementary Figs. 1A and 1B online illustrate the three-dimensional distribution of Sc and that of the corresponding vascular endothelium, respectively, obtained from stacks of 82 successive $0.5-\mu \mathrm{m}$-hick optical sections (all supplementary material is available in the online version of this article on the journal web site).

\section{DISCUSSION}

The present study proposes and validates an original technique that permits the triple fluorescence labeling of Sc, adrenergic varicosities, and associated vascular endothelium in large portions of the kidney. Our strategy was to take advantage of a protein S100B/EGFP transgenic mouse to directly visualize $\mathrm{Sc}$ within the kidney and combine it with lectin and immunohistochemical labelings.
Since the presently used S100B/EGFP transgenic mice have been validated only for the central nervous system $(17,46)$, we needed to assess what types of renal cells expressing EGFP were also positive for immunoreactive protein S100B. We found that epithelial cells populating the parietal layer of Bowman's capsules (48), proximal tubular loops, and thin limbs of Henle were strongly EGFP positive but were not concomitantly protein S100B positive. They thus demonstrated ectopic EGFP expressions in the S100B/EGFP transgenic mice. A similar conclusion was reached for a population of cells present on the adventitia of large intrarenal arteries. On the other hand, an EGFP-positive cell population was found within the perivascular space that concurrently expressed protein S100B and exhibited morphological characteristics of Sc $(15,27,28,39)$. Similarly, observation of the pelvic mucosa revealed a meshwork of EGFP- and protein S100B-positive cells with anatomic characteristics of Sc. Our present results are in keeping with earlier studies (32) showing the lack of protein S100B immunoreactivity in rat renal tubules and its presence in Sc of the renal pelvic nerves.

Although protein S100B is a classic marker of Sc (11, 13, $20,25,27,32,39,43)$, this protein is expressed by both fully differentiated myelinated and unmyelinated $\operatorname{Sc}(5,11,22,35)$. Hence, the presently used protein S100B/EGFP transgenic mice do not theoretically allow one to distinguish myelinated from unmyelinated Sc. Various considerations, however, allow us to solve this ambiguity. Ultrastructural studies of the extrinsic nerves leading to the kidney in mice $(36)$ and rats $(8,37)$ revealed that in both species myelinated fibers account for only a small percentage of the total number of renal nerve fibers, and this proportion is even less in terms of axons. Therefore, most of the EGFP-protein S100B-positive cells with anatomic characteristics of Sc presently observed in the perivascular space or within the pelvic mucosa likely represent the unmyelinated Sc population. Furthermore, myelinated fibers within the kidney are considered to be sensory afferent ones whereas the unmyelinated fibers are mostly adrenergic efferent ones $(2$, $9,29)$. We previously found that selective adrenergic denervation with 6-hydroxy dopamine (3) eliminated most of the immunostained synaptophysin along the preglomerular vasculature in rats (6). In the present study, we found a close proximity between Sc and synaptophysin staining (Figs. 6 and 7). Therefore, we may reasonably assume that the present technique allows the observation of the topological relationships between unmyelinated $\mathrm{Sc}$ and related adrenergic varicose axons within the kidney.

Use of an anti-synaptophysin antibody allowed us to observe the microtopology of Sc and associated adrenergic nerve varicosities along the preglomerular vasculature and within the pelvic mucosa (Figs. 6 and 7). In agreement with previous studies $(3,27,28,42)$, varicosities were organized as strings in close apposition to Sc processes and oriented toward the effector smooth muscle cells (Fig. 6, $A$ and $B$ ). In addition, many "free" varicosities were observed both around vessels and within the pelvic mucosa (Figs. 6 and 7) not associated with visible Sc processes. We cannot rule out that free varicosities were in fact associated with very fine Sc cell processes whose fluorescence was not detectable at the presently used magnifications (from $\times 10$ to $\times 60$ ) and microscopic system. Such very fine Sc cell processes are indeed visible with the high optical resolution achieved in Fig. 2. 

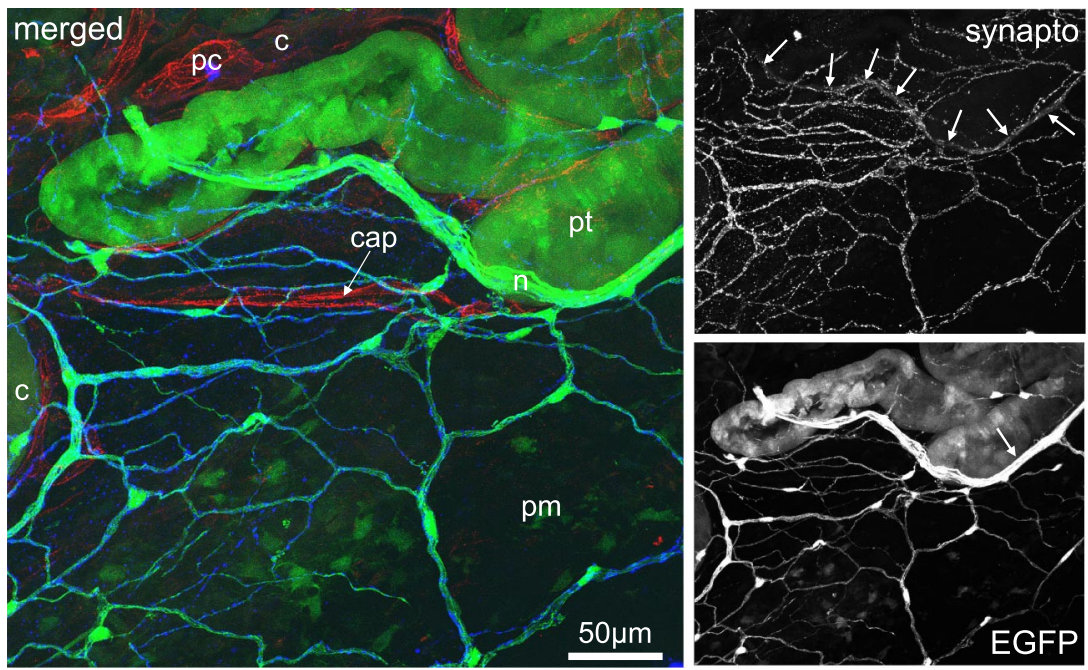

Fig. 7. Distribution of Sc and adrenergic axons within the pelvic mucosa This kidney section of an S100B/EGFP transgenic mouse $(\times 20$ objective, 52 optical sections, $0.5-\mu \mathrm{m}$ thickness) provides an en face view of the pelvic mucosa (pm) and shows its insertion to the juxtamedullary cortex (c) as seen from the urinary space. The merged panel combines lectin labeling (red), synaptophysin labeling (blue), and EGFP fluorescence (green). The latter 2 labelings are shown separately on the right. The pelvic mucosa covers proximal tubular loops (pt; note its strong ectopic EGFP expression in the merged panel), and an arcuate artery whose adventitial EGFP-positive cells are visible. Lectin labeling shows cortical peritubular capillaries (pc) and a capillary running within the pelvic mucosa (cap). A meshwork of interconnecting Sc with prominent cell bodies and long multiple cell processes populate the thickness of the pelvic mucosa and coalesce to form a nerve (n). Since the EGFP fluorescence of the nerve is overwhelming in the merged panel, the corresponding signal of synaptophysin was indicated by a series of white arrows in the synaptophysin panel (right). Many synaptophysin-positive varicosities run parallel to Sc processes, and some of them are not associated with visible Sc processes (merged panel) as was previously observed (Fig. 6). Note that most Sc of the pelvic mucosa are not associated with vessels.

Alternatively, a series of elegant scanning electron microscopic studies performed in nonrenal organs in rats, guinea pigs, and mice are worth mentioning. In these studies $(14,39$, $40,44)$, removal of the extracellular matrix by a partial digestion/maceration procedure allowed the observation of the fine topology and surface features of Sc and those of corresponding adrenergic axons. These observations were made in arterioles of the rat mammary gland (14), in the guinea pig urinary bladder (40), in the rat large intestine (44), and in the mouse pancreas (39). At magnifications varying from $\times 3,000$ to $\times 10,000$, varicose axons were consistently found to be either apposed, partly enclosed by Sc or their processes, or running free of Sc on top of the effector cells. These topological relationships between $\mathrm{Sc}$ and adrenergic varicose axons are fully consistent with our present confocal observations along renal vessels.

In the presently used protein S100B/EGFP transgenic mice, the EGFP protein synthesized by Sc diffused within the cells and allowed the direct imaging of fine cell processes within thick tissue sections (i.e., $\geq 50 \mu \mathrm{m}$ ). This fact and the optical sectioning capacity of confocal microscopy allowed the subsequent $3 \mathrm{D}$ reconstructions of $\mathrm{Sc}$ and accompanying vessels (Supplementary Fig. 1).

The glomerular efferent arterioles and their corresponding Sc and axons were not observed, although an adrenergic innervation has been previously documented along these vessels and along vasa rectae $(3,10,16)$. This limitation partly stems from the fact that Sc fluorescence was hindered by that of Bowman's capsules or by that of proximal tubular loops in the vicinity of glomerular vascular poles (Figs. 1 and 6). Nevertheless, this drawback must be weighed against the fact that efferent arterioles are characterized anatomically by a low innervation density $(3,30)$ and functionally by a lack of responsiveness to nervous stimulation (12).
One must note that the availability of mouse monoclonal antibodies against protein S100B purified from cow brain (Sigma) opens a possibility for the triple fluorescence labeling of Sc/axons/endothelium without using S100B/EGFP transgenic mice. The use of such an antibody has recently been reported in the brain or vas deferens of mice $(23,27)$, but, to the best of our knowledge, its application to vascular nerves and to renal tissue is unknown. Validation of such a technical alternative in renal vessels requires further study. Furthermore, one must underline that despite the problem of ectopic expression, S100B/EGFP transgenic mice offer the unique possibility of visualizing Sc in live specimens. Recordings of the activity of Sc are thus conceivable at the surface of renal vessels, using, for example, the mouse version of the juxtamedullary nephron preparation (18).

In conclusion, the present study validates a method that allows the triple fluorescence labeling of Sc, adrenergic varicosities, and associated vascular endothelium in large portions of the mouse kidney. Further studies are warranted to characterize this triad during renal development and in renal pathological models.

\section{ACKNOWLEDGMENTS}

Part of this study was presented as a poster at the FASEB Summer Research Conference Renal Hemodynamics: Biomolecular Control Mechanisms Integrating Vascular and Tubular Function, Vermont Academy, Saxtons River, Vermont, July 2007.

\section{GRANTS}

Funds were provided by the French Ministry of Research. S100B/EGFP transgenic mice were kindly provided by Dr. Catherine Legraverend (catherine. legraverend@igf.cnrs.fr; Institut de Génomique Fonctionnelle, Montpellier, France), who produced these animals $(17,46)$. 


\section{REFERENCES}

1. Autiero M, De Smet F, Claes F, Carmeliet P. Role of neural guidance signals in blood vessel navigation. Cardiovasc Res, 65: 629-638, 2005.

2. Barajas L, Wang P. Myelinated nerves of the rat kidney. A light and electron microscopic autoradiographic study. J Ultrastructural Res 65: $148-162,1978$.

3. Barajas L. Innervation of the renal cortex. Federation Proc 37: 1192 1201, 1978.

4. Basile JR, Castilho RM, Williams VP, Gutkind JS. Semaphorin 4D provides a link between axon guidance processes and tumor-induced angiogenesis. PNAS 103: 9017-9022, 2006.

5. Bhatheja K, Field J. Schwann cells: origins and role in axonal maintenance and regeneration. Int J Biochem Cell Biol 38: 1995-1999, 2006.

6. Casellas D, Bouriquet N, Artuso A, Walcott B, Moore LC. New method for imaging innervation of the preglomerular vasculature. Alterations in hypertensive rats. Microcirculation 7: 429-437, 2000.

7. Chen YY, McDonald D, Cheng C, Magnowski B, Durand J, Zochodne DW. Axon and Schwann cell partnership during nerve regrowth. $\mathrm{J} \mathrm{Neu-}$ ropathol Exp Neurol 64: 613-622, 2005.

8. DiBona GF, Sawin LL, Jones SY. Differentiated sympathetic neural control of the kidney. Am J Physiol Regul Integr Comp Physiol 271: R84-R90, 1996.

9. DiBona GF, Kopp UC. Neural control of renal function. Physiol Rev 77: 75-197, 1997.

10. Doležel S, Edvinsson L, Owman Ch Owman T. Fluorescence histochemistry and autoradiography of adrenergic nerves in the renal juxtaglomerular complex of mammals and man, with special regard to the efferent arteriole. Cell Tiss Res 169: 211-220, 1976.

11. Dong Z, Sinanan A, Parkinson D, Parmantier E, Mirsky R, Jenssen KR. Schwann cell development in embryonic mouse nerves. J Neurosci Res 56: 334-348, 1999 .

12. Fleming JT, Zhang C, Chen J, Porter JP. Selective preglomerular constriction to nerve stimulation in rat hydronephrotic kidney. Am J Physiol Renal Fluid Electrolyte Physiol 262: F348-F353, 1992.

13. Fornaro M, Tos P, Geuna S, Giacobini-Robecchi MG, Battiston B. Confocal imaging of Schwann-cell migration along muscle-vein combined grafts used to bridge nerve defects in the rat. Microsurgery 21: 153-155, 2001.

14. Fujiwara T, Uehara Y. The cytoarchitecture of the wall and the innervation pattern of the microvessels in the rat mammary gland: a scanning electron microscopic observation. Am J Anat 170: 39-54, 1984.

15. Funk D, Fricke C, Schlosshauer B. Aging Schwann cells in vitro. Eur J Cell Biol 86: 207-219, 2007.

16. Gosling JA, Dixon JS. The fine structure of the vasa recta and associated nerves in the rabbit kidney. Anat Rec 165: 503-514, 1969.

17. Hachem S, Lorenson AS, Hugnot JP, Legraverend C. Expression of S100B during embryonic development of the mouse cerebellum. $B M C$ Dev Biol 15: 17, 2007.

18. Harrison-Bernard L, Cook AK, Oliverio ML, Coffman TM. Renal segmental microvascular responses to ANG II in $\mathrm{AT}_{1 \mathrm{~A}}$ receptor null mice. Am J Physiol Renal Physiol 284: F538-F545, 2003.

19. Hayashi A, Koob JW, Liu DZ, Tong AY, Hunter DA, Parsadanian A, Mackinnon SE, Myckatyn TM. A double transgenic mouse used to track migrating Schwann cells and regenerating axons following engraftment of injured nerves. Exp Neurol 207: 128-138, 2007.

20. Hobson MI, Green CJ, Terenghi G. VEGF enhances intraneural angiogenesis and improves nerve regeneration after axotomy. J Anat 197: 591-605, 2000.

21. Jessen KR, Mirsky R. Schwann cells and their precursors emerge as major regulators of nerve development. Trends Neurosci 22: 402-410, 1999.

22. Jessen KR, Mirsky R. Signals that determine Schwann cell identity. $J$ Anat 200: 367-376, 2002.

23. Jinno S, Fleischer F, Eckel S, Schmidt V, Kosaka T. Spatial arrangement of microglia in the mouse hippocampus: a stereological study in comparison with astrocytes. Glia 55: 1334-1347, 2007.

24. Kaissling B, Kriz W. Structural analysis of the rabbit kidney. In: Advances in Anatomy Embryology and Cell Biology, edited by Brodal A,
Galveston WH, van Limborgh J, Ortmann R, Schiebler TH, Töndury G, and Wolff E. New York: Springer-Verlag, vol. 56, 1979.

25. Li J, Habbes HW, Eiberger J, Willecke K, Dermietzel R, Meier C. Analysis of connexin expression during mouse Schwann cell development identifies connexin29 as a novel marker for the transition of neural crest to precursor cells. Glia 55: 93-103, 2007.

26. Lietz M, Ullrich A, Schulte-Eversum C, Oberhoffner S, Fricke C, Müller HW, Schlosshauer B. Physical and biological performance of a novel block copolymer nerve guide. Biotechnol Bioeng 20: 1-11, 2005.

27. Lin YQ, Bennett MR. Varicosity-Schwann cell interactions mediated by ATP in the mouse vas deferens. J Neurophysiol 93: 2787-2796, 2005.

28. Lin YQ, Bennett MR. Schwann cells in rat vascular autonomic nerves activated via purinergic receptors. NeuroReport 17: 531-535, 2006.

29. Liu L, Barajas L. The rat renal nerves during development. Anat Embryol 188: 345-361, 1993.

30. Luff SE, Hengstberger SG, McLachlan EM, Anderson WP. Distribution of sympathetic neuroeffector junctions in the juxtaglomerular region of the rabbit kidney. J Auton Nerv Syst 40: 239-253, 1992.

31. Lyons DA, Pogoda HM, Voas MG, Woods IG, Diamond B, Nix R, Arana N, Jacobs J, Talbot WS. erbb3 and erbb2 are essential for Schwann cell migration and myelination in zebrafish. Current Biol 15: 513-524, 2005.

32. Molin SO, Rosengren L, Baudier J, Hamberger A, Haglid K. S-100 alpha-like immunoreactivity in tubules of rat kidney. A clue to the function of a "brain-specific" protein. J Histochem Cytochem 33: 367-374, 1985.

33. Mukouyama Ys Shin D, Britsch S, Taniguchi M, Anderson DJ. Sensory nerves determine the pattern of arterial differentiation and blood vessel branching in the skin. Cell 109: 693-705, 2002.

34. Nico B, Mangieri D, Benagiano V, Crivellato E, Ribatti D. Nerve growth factor as an angiogenic factor. Microvasc Res 75: 135-141, 2007.

35. Pau KY, Wolf DP. Derivation and characterization of monkey embryonic stem cells. Reprod Biol Endocrinol 16: 2:41, 2004.

36. Sassoli Fazan VP, Ma X, Chapleau MW, Barreira AA. Qualitative and quantitative morphology of renal nerves in C57BL/6J mice. Anat Rec, 268: 399-404, 2002.

37. Sato KL, Márcia do Carmo J, Sassoli Fazan VP. Ultrastructural anatomy of the renal nerves in rats. Brain Res 1119: 94-100, 2006.

38. Suchting S, Bicknell R, Eichmann A. Neuronal clues to vascular guidance. Exp Cell Res 312: 668-675, 2006.

39. Sunami E, Kanazawa H, Hashizume H, Takeda M, Hatakeyama K, Ushiki T. Morphological characteristics of Schwann cells in the islets of Langerhans of the murine pancreas. Arch Histol Cytol 64: 191-201, 2001.

40. Tachibana S, Takeuchi M, Fujiwara T. Visualization of autonomic varicose terminal axons by scanning electron microscopy. $J$ Electron Microsc 34: 136-138, 1985.

41. Takahashi-Iwanaga H, Iwata Y, Adachi K, Fujita T. The histotopography and ultrastructure of the thin limb of the Henle's loop: a scanning electron microscopic study of the rat kidney. Arch Histol Cytol 52: 395-405, 1989.

42. Taugner R, Hackenthal E. The Juxtaglomerular Apparatus: Structure and Function. New York: Springer-Verlag, 1989, p. 1-306.

43. Tohill MP, Mann DJ, Mantovani CM, Wiberg M, Terenghi G. Green fluorescent protein is a stable morphological marker for Schwann cell transplants in bioengineered nerve conduits. Tissue Engineering 10: 1359-1367, 2004.

44. Ushiki T. Three-dimensional ultrastructure of the autonomic nerve terminals in the lamina propria mucosae of the rat large intestine. Arch Histol Cytol 55, Suppl: 87-94, 1992.

45. van der Weyden L, Adams DJ, Bradley A. Tools for targeted manipulation of the mouse genome. Physiol Genomics 11: 133-164, 2002.

46. Vives V, Alonso G, Cohen-Solal A, Joubert D, Legraverend C. Visualization of S100B-positive neurons and glia in the central nervous system of EGFP transgenic mice. J Comparative Neurol 457, 404-419, 2003.

47. Yamamoto K, Wilson DR, Baumal R. Blood supply and drainage of the outer medulla of the rat kidney: scanning electron microscopy of microvascular casts. Anat Rec 210: 273-277, 1984.

48. Zhai XY, Birn H, Jensen KB, Thomsen JS, Andreasen A, Christensen EL. Digital three-dimensional reconstruction and ultrastructure of the mouse proximal tubule. J Am Soc Nephrol 14: 611-619, 2003. 